\title{
Effect of Platform Use on Satisfaction during the Waiting Time for Visiting Patients at a Dental Hospital
}

\author{
Seung Hee Jung ${ }^{1}$, Su Hyun Kim ${ }^{1}$, Hye Jeong Lee ${ }^{1}$, Min A Ji ${ }^{1}$, Young Eun Lee ${ }^{1}$ \\ ${ }^{1}$ Department of Dental Hygiene, Daegu Health College, Daegu, Republic of Korea
}

Objectives: While the number of dental hospitals and clinics is limited, as the number of patients increases, the problem of long waiting times has been continuously occurring. A platform was introduced to solve this issue and allow patients to spend their waiting time efficiently. In this study, the effect of hospital platform use on satisfaction was investigated by examining the perception of waiting time and the satisfaction and demand for platform use among the general public who have visited dental hospitals and clinics.

Methods: This study conducted an online survey on May 2021, targeting 109 adult men and women in their 20s and older who had visited a dentist located in Daegu and Gyeongbuk. For the survey, a structured self-report questionnaire consisting of a total of 7 items and 36 questions was used.

Results: The most frequently used medium by actual patients during waiting time was a mobile phone with $95.5 \%$, and the actual use of the deployed platform was low with $36.4 \%$. Among the platforms provided in dentistry, it was found that the use of the platform was highest when the platform was composed of booklets. In the dental platform, the majority of respondents wished to include information on preventive dental caries treatment including conservative treatment. The response that the provided platform is a great help in understanding dental care was positive with $39.1 \%$.

Conclusions: It will be helpful to increase the satisfaction of dental use by reflecting the behavior and needs of patients who spend waiting time and configuring the platform to have enough information about preventive dental caries treatment including conservative treatment in the form of a booklet and image platform.

Keywords: Waiting time, Dental hospitals and clinics, Platform, Patient satisfaction

Copyright (C) 2021. Korean Academy of Preventive Dentistry. All rights reserved.

This is an Open Access article distributed under the terms of the Creative Commons Attribution Non-Commercial License (http://creativecommons.org/licenses/ by-nc/4.0) which permits unrestricted non-commercial use, distribution, and reproduction in any medium, provided the original work is properly cited. 